(C)American Psychological Association, 2019. This paper is not the copy of record and may not exactly replicate the authoritative document published in the APA journal. Please do not copy or cite without author's permission. The final article is available, upon publication, at: https://doi.org/ 10.1037/pap0000274

\title{
Personality organization and maternal addiction: A structural-developmental psychodynamic contribution
}

\author{
Mauricio Alvarez-Monjaras ${ }^{\mathrm{a}}$, Helena JV Rutherford ${ }^{\mathrm{b}}$ \& Linda C Mayes ${ }^{\mathrm{b}}$ *
}

${ }^{a}$ Department of Clinical, Educational, and Health Psychology, University College London

${ }^{\mathrm{b}}$ Yale Child Study Center, Yale University School of Medicine

\section{Author Note}

This work was supported by the Mexican National Council for Science and Technology

(CONACYT) under scholarship 600356. The views presented are those of the authors and may not reflect those of the funding agencies who did not have input into the manuscript.

\section{Disclosure Statement}

None of the authors have any relevant financial disclosures.

*Correspondence concerning this article should be addressed to Linda C. Mayes, Yale Child Study Center, Yale University School of Medicine, 230 South Frontage Road, New Haven, CT, 06520. E-mail: linda.mayes@yale.edu 


\begin{abstract}
Motherhood has been deemed a normal crisis, given the significant psychological, biological, and neural changes surrounding pregnancy and the postpartum period. These challenges can become more complex as they are closely related to the parent's own selfdevelopment and sense of self-efficacy grounded in their personality prior to parenthood. The normal crisis of motherhood may be further complicated by addiction. Considering the evidence of the negative impact and poor developmental outcomes of children born to mothers with substance use disorders, special attention must be paid to addiction in this context. This paper is a review of evidence on the challenges of parenthood, particularly when affected by addiction. We explore the centrality of object relations in personality development and parenting practices and discuss the problem of maternal addiction from multiple perspectives, particularly Blatt's (1991a) two-polarities model of personality development.
\end{abstract}

Key words: motherhood, addiction, psychoanalysis, object relations, personality. 


\section{Introduction}

Mothers are the first environment their offspring encounter in their process of development; therefore, it is essential to understand how maternal behavior, sensitivity, and personality interplay with the developing psyche of the child. Motherhood can be a very challenging task given the significant psychological, biological, and neural changes surrounding pregnancy and the postpartum period. The transition to parenthood is also characterized by changes in interpersonal interactions, social demands and expectations of being a parent, conscious and unconscious wishes and fantasies related to their child and the parental experience, and sometimes disappointments from not meeting the individual parenthood ideals (Priel \& Besser, 2001; Von Mohr, Mayes, \& Rutherford, 2017).

These challenges -typical of parenthood-can become more complex as they are closely related to the parent's own self-development and sense of self-efficacy, grounded in their personality prior to parenthood. Therefore, maternity could be thought of as a particularly vulnerable period for women already struggling with self-control and emotion dysregulation and this may be particularly true in mothers with substance use disorders (SUDs). Considering the growing evidence underscoring the negative impact and poor developmental outcomes of children born to mothers with SUDs (e.g. Salo \& Flykt, 2013), special attention must be paid to addiction in the context of maternity in order to minimize risk and prevent the perpetuation of SUDs across generations.

The structural-developmental psychodynamic - or "two polarities"- model of personality development (Blatt, 1991a) offers a valuable framework to consider addiction in the context of motherhood. Grounded on cognitive, humanistic, and psychodynamic theories of development, the model was initially developed to empirically study depression (Shahar \& Mayes, 2017). Blatt 
(1991a) proposed that as human beings develop, they are faced with the dialectic transaction between fostering and tending to relationships and attachment bonds (i.e., interpersonal relatedness or anaclitic processes), and developing an independent and fully differentiated sense of self (i.e., self-definition or introjective process). Extreme reliance on one process over the other may lead to psychopathology or severe distortions of experiences and result in extremely dependent or self-critical strategies in interpersonal interactions (Berman, 2017; Blatt, 1991a; Blatt \& Luyten, 2009). However, under favorable circumstances, humans are able to integrate both polarities into a mature, integrated, and socially embedded sense of self. While the two polarities model was originally focused on individual personality development and initially focused on the first 11 years of life, it was later expanded to consider development across the lifespan (Blatt \& Luyten, 2009). Further, it has been argued that the model might facilitate understanding of the intergenerational transmission of attachment styles and psychopathology, including SUDs (Beebe \& Lachman, 2017; Priel \& Besser, 2001; Blatt and Luyten, 2013; Liden \& Suchman, 2013; Luyten, 2017; Soenens, Vansteenkiste, \& Luyten, 2010).

This paper is a review of evidence on the challenges of motherhood, specifically in relation to substance abuse. The paper will explore the centrality of object relations in personality development and parenting practices. Next, in line with recommendations by Blatt and Luyten (2009) inviting research efforts to be oriented towards the examination of the impact of neurobiological and genetic dimensions on psychological development, we discuss the problem of addictions from multiple perspectives, incorporating object relations, Blatt's (1991a) personality organizations, and a recently proposed developmental model of addiction (AlvarezMonjaras, Mayes, Potenza, Rutherford, 2018).

\section{Motherhood: A normal crisis}


Motherhood has been considered a "normal crisis" (Pines, 1972). Although highly rewarding and meaningful under ideal circumstances, becoming a parent may also be stressful and overwhelming. The complexity of the emotional experiences surrounding motherhood reflects both the hormonal, neurobiological, social, and intrapsychic processes that take place during the transition to motherhood, as well as this being a period of time where mothers revisit their own memories and representations of being parented to (1) internalize the newborn, (2) resolve early conflict, and (3) identify available resources to apply in the new caregiving tasks (Pines, 1972; Priel \& Besser, 2001; Von Mohr et al., 2017)

In line with Blatt's (1991a) model, the internal world of mothers and their children -both during and after pregnancy- are essential to understand motherhood (Blum, 2017). Object relations are dynamic systems or "internal working models" that guide behaviors, attitudes, and expectations, and help an individual make sense of themselves, others, and relationships (Auerbach \& Diamond, 2017). Even before birth, an expectant mother may hold a mental representation of the newborn, with a series of conscious and unconscious fantasies associated with them. Some mothers, for instance, may have idealized phantasies of their unborn child (e.g., “perfect in every way”, "a fulfilment of my life”, Sorenson \& Schuelke, 1999), others may talk about fantasies of symbiosis or fusion (e.g., envisioning themselves encompassing the fetus, Blum, 2017), or be more anxious and concerned by persecutory fantasies (e.g., parasitic fetus or depletion, Raphael-Leff, 1996). Considering that these representations guide behaviors and attitudes, some mothers might feel better prepared than others to take on the caregiving task.

In line with this, studies have shown that the content of internal representations can have a considerable impact on mother-child interactions. For instance, fantasies around childbirth can impact the decision of primiparous mothers regarding whether or not to request cesarean section 
-this was especially true for mothers that were more inclined to project negative or unwanted thoughts, feelings, fantasies, and motives (Handelzalts, Fisher, Sadan \& Goldzweig, 2017). Likewise, other studies have reported that mental representations of breastfeeding and the feeding interaction (e.g., comfort, rejection, crying, etc.) may also impact how mothers approach breastfeeding, and even the decision to switch to bottle-feeding (Kronborg et al., 2015; Sayre et al., 2001). Mental representations impacting parenting behavior extend beyond infancy, including during play interactions and in relation to parental control practices (Crawford \& Benoit, 2009; Soenens et al., 2010).

The quality (i.e., coherence, flexibility, and richness) of internal representations may also affect a mother's capacity to make sense and adapt their own behavior to sensitively and appropriately respond to their child's preverbal demands and mental states (Alvarez-Monjaras, McMahon \& Suchman, 2017; Fonagy, Gergely \& Target, 2007; Fonagy, Steele, Steele, Moran, \& Higgitt, 1991). For instance, mothers with disengaged representations in the Adult Attachment Interview (George, Kaplan, \& Main, 1985) tend to be less sensitive, more passive, and less encouraging, while those with more coherent representations engage in less negative (e.g., aggressive or intrusive) and more positive (e.g., warm or soothing) parenting practices (Slade, Belsky, Aber \& Phelps, 1999; Sokolowsky, Hans, Bernstein, \& Cox, 2007). Thus, the overall quality of mental representations allows for mothers to engage more sensitively with their child.

\section{Maternal object relations and the internal world of the child}

Recent studies have argued that not only do these object representations influence maternal behaviors but they might also be passed on across generations via the mother's capacity to think about and interpret their own and their infant's behavior in terms of mental states and intentions (termed reflective functioning; Fonagy et al., 2007). A caregiver's reflective 
functioning -inherently associated with mental representations (Alvarez-Monjaras et al., 2017)has been considered the missing link in the well-known intergenerational transmission of attachment patterns and relational knowledge (Fonagy \& Allison, 2014). Through these marked, ostensive, and contingent feedback reactions towards the infant's automatic behavioral expressions (i.e., parental sensitivity), the caregiver slowly sensitizes the child to primary and secondary mental states and intentions in oneself and others (Fonagy \& Bateman, 2008; Fonagy et al., 2007). This "natural pedagogy" (Csibra \& Gergely, 2009) fosters self-awareness and selfregulation capabilities by allowing the child to learn from others and become attuned to personally-relevant learning opportunities (Fonagy \& Allison, 2014). Further, it is through the continuous modelling and shaping of this psychic stance, that humans are thought to learn to adapt to increasingly complex social interactions, including parenting (Fonagy, Gergely, Jurist, \& Target, 2002).

Transmission of attachment patterns and the resulting personality organizations were originally thought of to be unidirectional from mother to infant (Fonagy et al., 1991). However, despite the important role of mothers, recent studies have argued that rather than a direct 'transmission', it is more of a 'co-creation' based on behavioral repertoires and the interplay of both the mother's and the infant's internal organizations across infancy and child development (Beebe \& Lachman, 2017). Therefore, the representations of self, other, and self-with-other, within the child and the mother change as the infant develops. The child is developing the internal psychic structures towards object constancy, which in turn allows cognitive processes to flourish (Blatt, 1991a). In these moments, the mother is both (1) developing new schemas about her child, and (2) progressing back and forth between previous modes of functioning and attempts towards her own self-constancy (Blatt \& Luyten, 2009). 


\section{Maternal addiction: A special scenario}

The structural-developmental psychodynamic model has been employed to understand the etiology, development, and transmission of depression and dysthymic psychopathologies. Luyten, Blatt, and Fonagy (2013) have also argued that the model could help explain individual vulnerabilities to develop certain clinical symptoms or disorders -such as addiction- which have been found to be characterized by impairments in the sense of self and relatedness.

SUDs are defined as the recurrent use of psychoactive drugs that cause significant clinical and functional impairment and failure to meet major life responsibilities, evidenced by impaired self-control, compromised social interactions, risky use, and pharmacological indicators such as tolerance and withdrawal (American Psychiatric Association, 2013). Multiple risk factors have been associated with substance use and abuse. From a neurobiological perspective, SUDs are a series of neuroadaptations to repeated substance use which impact reward processing, executive functioning, and emotion regulation capacities, all of which are essential for caregiving behavior (Alvarez-Monjaras et al., 2018; Johnson, 2001; Rutherford, Potenza, \& Mayes, 2013). Twin, adoption, and molecular genetic studies have established that SUDs have a significant heritable component; however, findings suggest that it is the interaction between genes and environmental circumstances that may be most responsible for predisposing individuals to drug use, abuse, and dependence (see Goldman, Oroszi, \& Ducci, 2005).

Psychodynamic theory explains addiction as a consequence of compromised object relations, problems in self-development, and a poor containment of unrepresented mental states (Krystal, 1978; Morgenstern, \& Leeds, 1993; Sweet, 2013). A critical role of caregivers is to help their offspring to differentiate, metabolize, and make sense of their internal and external realities (Fonagy et al., 2002; Winnicott, 1960). Failure to do so, may be experienced by the 
infant as highly distressing states of mind that are thought to thwart the infant's ability to tolerate ambivalence - a feature of object constancy- and gradually move towards self-constancy (Auerbach \& Diamond, 2017; Blatt, 1991a; Blatt \& Luyten, 2009). Remarkably, the unconscious fantasies resulting from these unrepresented states of mind have been described in terms resembling both anaclitic (Spitz \& Wolf, 1946) and introjective (Freud, 1917) positions, which raises the question of whether these early failures may themselves lay the ground for psychopathology later in development (Flores, 2001, 2011; Johnson, 2001). In fact, Krystal (1978) proposed a "basic defect" in the process of separation-individuation as central to addictive behaviors, suggesting that the alexythimic and affect-regulation difficulties -as well as the aggression commonly observed in the treatment of addicted individuals- may be explained as fear responses to the reemergence of an "original trauma" (Bean, Khantzian, Mack, Vaillant, \& Zinberg, 1981; Director, 2002).

Notwithstanding these early setbacks, most individuals with SUDs develop a more mature and realistic psychological mode of functioning; however, this developmental achievement may not be sufficient given the absence of "containment" or psychological support from early caregivers (Bion, 1962; Morgenstern, \& Leeds, 1993; Sweet, 2013). Consequently, in the face of stress or major life changes, these individuals may be more prone to retreat to more primitive states of mind and behaviors (Kernberg, 1975; Sinha, 2001; Krystal, 1978). Therefore, addiction may also be understood as an -albeit maladaptive- attempt to transact environmental and intrapsychic conflicts, where either (1) a failure in the ability to evoke the soothing qualities of the good internal object (i.e. an anaclitic failure), or (2) a failure to control or "wall-off" the distressing qualities of the bad internal object qualities (i.e. an introjective failure) result in the use of different substances and their excessive intake (Alvarez-Monjaras et al., 2018; Krystal \& 
Raskin, 1970; Waska, 2006). Consistent with this notion, Blatt, Rounsaville, Eyre, and Wilbur (1984) identified an important role of self-criticism and guilt in the development of opiate addiction; whereas Lidz, Lidz, and Rubenstein (1975) identified an association between the anaclitic personality traits and the development of amphetamine addiction. Therefore, it is possible -just as is the case for maternal behavior- that the different behavioral strategies of each personality organization lead to different stances towards drug use. This is similar to Khantzian's (1987) "self-medication" hypothesis whereby addiction-prone individuals tend to gravitate to certain drug properties that fulfil their specific individual self-regulatory deficits (e.g. self-care, self-control, self-repair) (Khantzian, Halliday, \& Mcauliffe, 1990).

\section{Addiction and personality}

Blatt (1991a) suggested that inconsistent or split object relations are characteristic of 'borderline' personality organizations (Kernberg, 1975), in which object constancy has not yet been attained. Interestingly enough, borderline personality disorders have been found to often cooccur with SUDs (Grant et al., 2008). Therefore, psychotherapy research has recently focused on interventions for this group of clients with promising effectiveness findings in short- and longterm outcomes (Gregory, DeLucia-Deranja, \& Mogle, 2010, Gregory et al., 2008; Gregory, Remen, Soderberg, \& Ploutz-Snyder, 2009; Suchman et al., 2010, 2017). The problem herein lies, however, in the consequences this may pose to caregiving, given the evidence that early adversity -and the resulting representational disruptions- may lead to greater affect regulation difficulties and problems in developing rewarding and nurturing relationships, thus increasing their vulnerability to drug use as a means of coping (Crittenden, 2015; Flores, 2011; Fonagy et al., 2002, 2008). 
Unresolved and insecure attachment representations -characterized by emptiness, inconsistency, and fragmentation (Speranza, Nicolais, Vergano, \& Dazzi, 2017)- are indeed more common in mothers with SUDs than in those without SUDs (Bean et al., 1981; Isosävi et al., 2016; Sokolowsky et al., 2007; Suchman, DeCoste, Rosenberger, \& McMahon, 2012). It has been argued that the internalization of a negative attachment figure - a common consequence of early traumatic experiences — might lead to a learned "fear" of minds altogether (Fonagy \& Bateman, 2008; Sweet, 2003). This resulting lack of coherence in the mother's mental representations may render her incapable of using her own ability to make sense of the child's unrepresented mental states (Alvarez-Monjaras et al., 2017). In other words, the mother may misattribute the child's behavior or, even worse, become so distressed by the behaviors that she may project her own unrepresented attachment experiences onto the child. This may in turn mobilize the child to enact these behavioral patterns via projective identification (Klein, 1946) and lead to greater dyadic distress.

These forms of dysregulating interactions may resemble a pattern of co-dysregulation. A microanalysis of behavioral transactions of 126 mother-infant dyads evidenced that highly selfcritical mothers showed more attentional withdrawal and less emotional coordination, and -even though they would compensate by touching their infants frequently- their infants would withdraw themselves and attempt at self-regulating through rhythmic vocal sounds (Beebe \& Lachman, 2017). Consequently, the greater difficulty for mothers joining their infants emotional experience (possibly due to internal negative self-representations and concerns) may result in similar avoidant strategies in their infants in later life. Notably, Beebe and Lachman (2017) reported that more dependent mothers showed hypervigilance and a tendency to hyper-arouse their infants by engaging long gazes and overreacting to the infant's cues, which would result in 
their infants looking away and disengaging for long periods in order to self-regulate. Such a heightened level of social vigilance may lead to similar dependent strategies in their infants later in development.

Taken together, the findings from Beebe and Lachman (2017) underscore the importance of the child's internal world and temperament in the co-creation of these relational transactions and intergenerational transmission of relational patterns. Now, considering the evidence of compromised object relations and their negative impact on mother-infant interactions and development, and that prenatal exposure to drugs may make infants more irritable and difficult to soothe (Eiden, Schuetze, \& Coles, 2011; Siqveland, Haabrekke, Wentzel-Larsen, \& Moe, 2014), the transition to parenthood and associated caregiving responsibilities could come at a higher cost for mothers with pre-existing SUDs. Moreover, the above evidence might lend insight to understanding why children born to mothers with SUDs may have a greater risk of also developing insecure or disorganized attachment patterns, which have been proposed as important risk factors for developing a SUD later in life (Crittenden, 2015; Flores, 2001; Morgenstern \& Leeds, 1993; Rodning, Beckwith, \& Howard, 2008).

\section{Personality organization, addiction, and the challenges of motherhood}

Mothers with SUDs have been found to have multiple caregiving difficulties, including reduced sensitivity to infant cues (Alvarez-Monjaras et al. 2018), compromised mental representations (Lyden \& Suchman, 2013), and impaired parental reflective functioning (Suchman, DeCoste, Leigh, \& Borelli, 2010). These difficulties may also be explained by other factors associated with addiction, including sociodemographic risk, early attachment trauma, or psychopathology (Espinosa, Beckwith, Howard, Tyler, \& Swanson, 2001; Freeman, Collier, \& 
Parillo, 2002; Kaltenbach, 2013; Suchman \& Luthar, 2000). Importantly, personality features have also been implicated (Suchman, McMahon, DeCoste, Castiglioni, \& Luthar, 2008).

Particularly in relation to maternal behavior, mothers addicted to opioids tend to be harsher, more authoritarian, and less responsive with their infants when compared to nonsubstance-using mothers (Bernstein, Jeremy, Hans, \& Marcus, 1984). Interestingly, similar behavioral patterns have been attributed to introjective or self-critical personality organizations (Beebe \& Lachman, 2017; Blatt \& Luyten, 2009; Soenens et al., 2010). Furthermore, Luyten (2017) discussed associations between self-critical organizations and vulnerability to stress, also a key vulnerability factor for developing SUDs (Sinha, 2001; Suchman \& Luthar, 2001; Tops, Koole, IJzerman, \& Buisman-Pijlman, 2014). Although no studies thus far have studied the association of personality style, addiction, and parenting, multiple sources of evidence indicate a particular vulnerability around introjective personality organizations; however, it is also possible that anaclitic organizations could develop other forms of impulsive or compulsive behavior (e.g., eating disorders, pathological promiscuity, parasuicidal behaviors, etc., Blatt, 1991b; Corcos et al., 2008; Larson, \& Johnson, 1985).

A recently published developmental model of addiction (Alvarez-Monjaras et al., 2018) suggests that SUDs may be better understood as developmental, rather than purely neurochemical, disorders. The authors argue that, beyond the structural and functional changes associated with substance abuse, it is the interaction between genetic, epigenetic, neurobiological factors, and adverse caregiving experiences during key developmental stages that increases the risk for the development of addiction. Such a notion resonates with converging research evidencing that SUDs and attachment mechanisms have overlapping neural pathways, specifically dopaminergic (i.e., reward) and oxytocinergic systems (i.e., self-regulation and 
social behaviors) (Buisman-Pijlman et al., 2014; Insel, 2003; Tops et al., 2014). On the one hand, substance misuse leads to diminished salience of infant cues (Rutherford \& Mayes, 2017; Rutherford, Potenza, \& Mayes, 2013; Rutherford, Williams, Moy, Mayes, \& Johns, 2011) and, on the other, early stress and traumatic attachment experiences may thwart the development of the endogenous oxytocinergic system, thus increasing vulnerability to future SUDs (Flores, 2001; Sinha, 2001; Tops et al., 2014). Given its focus on attachment, it might support relational formulations of addiction (e.g., Director, 2002) as well as psychodynamically informed treatment models, such as dynamic deconstructive psychotherapy (Gregory \& Remen, 2008) or mentalization-based therapy (Fonagy \& Bateman, 2008).

Given the hypothesized overlapping neural circuitry of addiction and attachment, individuals with introjective or self-critical personalities might be at a greater disadvantage during the transition to the parenting role and, potentially, at a greater risk of substance use difficulties more generally. This could in part because (1) they may be more likely to attribute their own sense of achievement and self-worth to their parenting tasks and may thus be particularly vulnerable to misinterpreting normal parental stressors (e.g., child crying, rejection, or protest) as signs of failure (i.e., parenting as distressing rather than rewarding), (2) and because their derogation of relational rewards may make it harder for them to use attachment strategies and pathways to down-regulate (i.e., higher vulnerability to stress). This personality vulnerability might be further increased in individuals with adverse or traumatic experiences, socioeconomic disadvantage, chronic physical health problems, or mental health difficulties; all of which are known to increase stress (Sinha, 2001). Therefore, it would be relevant for future research to more thoroughly explore the association between SUDs and personality organizations. Further, it is clinically important to (1) identify these individual and 
environmental vulnerabilities as early as possible and start addressing them prenatally, and (2) avoid blaming or guilt-inducing in mothers with a SUDs. This might in itself help prevent further deterioration in the mother-child relationship and could facilitate treatment efforts to address both the addiction and the dyadic relationship (Suchman et al., 2012).

\section{Conclusion}

The transition motherhood is a complex and demanding process. Sometimes, without much warning or preparation, a woman must undergo a series of hormonal, neurobiological, social, and psychological changes in order to provide an appropriate environment for the unborn child. Even with a planned pregnancy, these changes are often profound and quite sensitive to environmental and hereditary factors. Motherhood can come at a particularly great cost for some mothers, especially those with compromised object relations. Mothers with a SUD — particularly those with a self-critical personality organization — may find it especially difficult to handle these demands and might be at a markedly high risk of engaging in problematic interactive patterns with their offspring. It is therefore relevant for research efforts to focus on enhancing our understanding of the impact of personality organizations on addictive processes. Likewise, as encouraged by Blatt (Dimitrovsky, 2007), clinical efforts should be geared towards helping addicted mothers to "free" the adaptive, growth-oriented representations that will help the dyad co-construct more flexible personalities and, in turn, prevent this and other forms of psychopathology.

\section{References}

Alvarez-Monjaras, M., McMahon, T., \& Suchman, N. (2017). Does maternal reflective functioning mediate associations between representations of caregiving and maternal 
sensitivity in a high-risk sample?. Psychoanalytic Psychology. 36(1), 82. DOI:

10.1037/pap0000166

Alvarez-Monjaras, M., Mayes, L., Potenza, M., \& Rutherford, H. (2018). A developmental model of addictions: Integrating neurobiological and psychodynamic theories through the lens of attachment. Attachment and Human Development, 1-22. DOI:

$10.1080 / 14616734.2018 .1498113$

American Psychiatric Association. (2013). Diagnostic and statistical manual of mental disorders (5th ed.). Washington, DC: Author.

Auerbach, J., \& Diamond, D. (2017). Mental representation in the thought of Sydney Blatt: Developmental Process. Journal of the American Psychoanalytic Association, 65(3), 509523. DOI: $10.1177 / 0003065117709582$

Bean, M., Khantzian, E., Mack, J., Vaillant, G., \& Zinberg, N. (1981). Dynamic approaches to the understanding and treatment of alcoholism. New York: The Free Press.

Beebe, B., \& Lachman, F. (2017). Maternal self-critical and dependent personality styles and mother-infant communication. Journal of the American Psychoanalytic Association, 65(3), 491-508. DOI: 10.1177/0003065117709004

Berman, E. (2017). An inclusive psychoanalyst: Sydney Blatt 's contribution in perspective. Journal of the American Psychoanalytic Association, 65(3), 523-533. DOI: $10.1177 / 0003065117709030$

Bernstein, V., Jeremy, R., Hans, S., \& Marcus, J. (1984). A longitudinal study of offspring born to methadone-maintained women. II. Dyadic interaction and infant behavior at 4 months. The American Journal of Drug and Alcohol Abuse, 10(2), 161-193. DOI:

$10.3109 / 00952998409002779$ 
Bion, W. (1962). Learning from experience. London, England: Karnak.

Blatt, S. (1991a). A cognitive morphology of psychopathology. Journal of Nervous and Mental Disease, 179(8), 449-458.

Blatt, S. (1991b). Depression and destructive risk-taking behavior in adolescence. In L. Lipsitt and L. Mitnick (Eds.), Self-regulatory Behavior and Risk Taking: Causes and Consequences. Westport, CT: Greenwood Publishing Group.

Blatt, S., \& Luyten, P. (2009). A structural-developmental psychodynamic approach to psychopathology: Two polarities of experience across the lifespan. Development and Psychopathology, 21, 793-814. DOI: 10.1017/S0954579409000431

Blatt, S., \& Luyten, P. (2013). Interpersonal relatedness and self-definition in normal and disrupted personality development. American Psychologist, 68(3), 172-183. DOI: $10.1037 / \mathrm{a} 0032243$

Blatt, S., Rounsaville, B., Eyre, S., \& Wilbur, C. (1984). The psychodynamics of opiate addiction. Journal of Nervous and Mental Disease, 172, 342-352.

Blum, H. (2017). The mother's mental representation of her infant. International Forum of Psychoanalysis, 26(1), 64-69. DOI: 10.1080/0803706X.2016.1184311

Buisman-Pijlman, F., Sumracki, N., Gordon, J., Hull, P., Carter, S., \& Tops, M. (2014). Individual differences underlying susceptibility to addiction: Role of the endogenous oxytocin system. Pharmacology, Biochemistry and Behavior, 119, 22-38. DOI: 10.1016/j.pbb.2013.09.005

Corcos, M., Loas, G., Speranza, M., Perez-Diaz, F., Stephan, P., Verrier, A., Lang, F., Nezelof, S., Bizouard, P., Venisse, J., \& Jemmet, P. (2008). Risk factors for addictive disorders: A 
discriminant analysis on 374 addicted and 513 nonpsychiatric participants. Psychological Reports, 102, 435-449. DOI: 10.2466/pr0.102.2.435-449

Crawford, A., \& Benoit, D. (2009). Caregivers' disrupted representations of unborn child predict later infant caregiver disorganized attachment and disrupted interactions. Infant Mental Health Journal, 30(2), 124-144. DOI: 10.1002/imhj.20207

Crittenden, P. (2015). Danger, development and adaptation. Hampshire, England: Waterside Press.

Csibra, G., \& Gergely, G. (2009). Natural pedagogy. Trends in Cognitive Sciences, 13, 148-153. DOI: 10.1016/j.tics.2009.01.005

Dimitrovsky, L. (2007). Interview with Prof. Sidney Blatt. The Israel Journal of Psychiatry \& Related Sciences, 44(4), 309-320.

Director, L. (2002). The value of relational psychoanalysis in the treatment of chronic drug and alcohol use. Psychoanalytic Dialogues, 12(4), 551-579. DOI: 10.1080/10481881209348689

Eiden, R., Schuetze, P., \& Coles, C. (2011). Maternal cocaine use and mother-infant interactions: Direct and moderated associations. Neurotoxicology and Teratology, 33, 120-128. DOI: 10.1016/j.ntt.2010.08.005

Espinosa, M., Beckwith, L., Howard, J., Tyler, R., \& Swanson, K. (2001). Maternal psychopathology and attachment in toddlers of heavy cocaine-using mothers. Infant Mental Health Journal, 22(3), 316-333. DOI: 10.1002/imhj.1004

Flores, P. (2001). Addiction as an attachment disorder: Implications for group therapy. International Journal of Group Psychotherapy, 51(1), 63-81. DOI: 10.1521/ijgp.51.1.63.49730

Flores, P. (2011). Addiction as an attachment disorder. New York: Jason Aronson. 
Fonagy, P., \& Bateman, A. (2008). Mentalization-based treatment of borderline personality disorder. In E. Jurist, A. Slade, \& S. Bergner (Eds.), Mind to mind: Infant research, neuroscience, and psychoanalysis. New York, NY: Other Press.

Fonagy, P., \& Allison, E. (2014). The role of mentalizing and epistemic trust in the therapeutic relationship. Psychotherapy, 51(3), 372. DOI: 10.1037/a0036505

Fonagy, P. Gergely, G., Jurist, E., \& Target, M. (2002). Affect regulation, mentalization and the development of the self. New York, NY: Other Press.

Fonagy, P., Gergely, G., \& Target, M. (2007). The parent-infant dyad and the construction of the subjective self. Journal of Child Psychology and Psychiatry, 48(3-4), 288-328. DOI: $10.1111 / \mathrm{j} .1469-7610.2007 .01727 . \mathrm{x}$

Fonagy, P., Steele, M., Steele, H., Moran, G., \& Higgitt, A. (1991). The capacity for understanding mental states: The reflective self in parent and child and its significance for security of attachment. Infant Mental Health Journal, 12(3), 201-218. DOI: 10.1002/10970355(199123)12:3<201::AID-IMHJ2280120307>3.0.CO;2-7

Freeman, R., Collier, K., \& Parillo, K. (2002). Early life sexual abuse as a risk factor for crack cocaine use in a sample of community-recruited women at high risk for illicit drug use. The American Journal of Drug and Alcohol Abuse, 28(1), 109-131. DOI: 10.1081/ADA120001284

Freud, S. (1917). Mourning and melancholia. In J. Strachey (Ed. \& Trans.), The standard edition of the complete psychological works of Sigmund Freud (Vol. 14). London, England: The Hogarth Press \& The Institute of Psychoanalysis.

George, C., Kaplan, N., \& Main, M. (1985). Adult Attachment Interview. Unpublished manuscript. University of California, Berkeley, California, CA. 
Goldman, D., Oroszi, G., \& Ducci, F. (2005). The genetics of addictions: uncovering the genes. Nature Reviews Genetics, 6(7), 521. DOI: 10.1176/foc.4.3.401

Grant, B., Chou, S., Goldstein, R., Huang, B., Stinson, F., Saha, T., Dawson, D., Smith, S., Ruan, W., Pulay, A., \& Pickering, R. (2008). Prevalence, correlates, disability and comorbidity of DSM-IV borderline personality disorder: Results from the Wave 2 National Epidemiologic Survey on Alcohol and Related Conditions. Journal of Clinical Psychiatry, 69, 533-545. DOI: $10.1176 /$ foc. 4.3 .401

Gregory, R., Chlebowski, S., Kang, D., Remen, A., Soderberg, M., Stepkovitch, J., \& Virk, S. (2008). A controlled trial of psychodynamic psychotherapy for co-occurring borderline personality disorder and alcohol use disorder. Psychotherapy: Theory, Research, Practice, Training, 45, 28-41. DOI: 10.1037/0033-3204.45.1.28

Gregory, R., DeLucia-Deranja, E., \& Mogle, J. (2010). Dynamic deconstructive psychotherapy versus optimized community care for borderline personality disorder co-occurring with alcohol use disorders: A 30-month follow-up. Journal of Nervous and Mental Disease, 198, 292-298. DOI: 10.1097/NMD.0b013e3181d6172d

Gregory, R., \& Remen, A. (2008) A manual-based psychodynamic therapy for treatmentresistant borderline personality disorder. Psychotherapy. 45, 15-27. DOI: 10.1037/00333204.45.1.15

Gregory, R., Remen, A., Soderberg, M., \& Ploutz-Snyder, R. (2009). A controlled trial of psychodynamic psychotherapy for co-occurring borderline personality disorder and alcohol use disorder: Six-month outcome. Journal of the American Psychoanalytic Association, 57, 199-205. DOI: 10.1177/00030651090570011006 
Handelzalts, J., Fisher, S., Sadan, O., \& Goldzweig, G. (2017). Object relations, unconscious defences and fear of childbirth, as reflected in maternal request caesarean section. Journal of Reproductive and Infant Psychology, 35(1), 91-102. DOI: 10.1080/02646838.2016.1253832

Isosävi, S., Flykt, M., Belt, R., Posa, T., Kuittinen, S., Puura, K., \& Punamäki, R. (2016). Attachment representations among substance-abusing women in transition to motherhood: implications for prenatal emotions and mother-infant interaction. Attachment \& Human Development, 18(4), 391-417. DOI: 10.1080/14616734.2016.1151904

Insel, T. (2003). Is social attachment an addictive disorder?. Physiology \& Behavior, 79(3), 351357. DOI: $10.1016 / \mathrm{S} 0031-9384(03) 00148-3$

Johnson, B. (2001). Drug dreams: A neuropsychoanalytic hypothesis. Journal of the American Psychoanalytic Association, 49, 75-96. DOI: 10.1177/00030651010490011101

Kaltenbach, K. (2013), Biopsychosocial characteristics of parenting women with substance use disorders. In N. Suchman, M. Pajulo, \& L. Mayes (Eds.), Parenting and substance abuse: Developmental approaches to intervention. New York, NY: Oxford University Press.

Kernberg, O. (1975). Borderline conditions and pathological narcissism. New York, NY: Aronson.

Khantzian, E. (1987). The self-medication hypothesis of addictive disorders: focus on heroin and cocaine dependence. The American Journal of Psychiatry, 142(11), 1259-1264. DOI: 10.1007/978-1-4613-1837-8_7

Khantzian, E., Halliday, K. \& Mcauliffe, W. (1990). Addiction and the vulnerable self. New York: Guilford.

Klein, M. (1946). Notes on some schizoid mechanisms. The International Journal of Psychoanalysis, 27, 99-110. 
Krystal, H. (1978). Self representation and the capacity for self care. The Annual of Psychoanalysis, 6, 209-246.

Krystal, H., \& Raskin, H. (1970). Drug dependence: Aspects of ego function. Detroit: Wayne State University Press.

Kronborg, H., Harder, I., \& Hall, E. (2015). First time mothers' experiences of breastfeeding their newborn. Sexual and Reproductive Healthcare, 6, 82-87. DOI: 10.1016/j.srhc.2014.08.004

Larson, R., \& Johnson, C. (1985). Bulimia: Disturbed patterns of solitude. Addictive Behaviors, 10(3), 281-290. DOI: 10.1016/0306-4603(85)90009-7

Lyden, H., \& Suchman, N. (2013). Transmission of parenting models at the level of representation: Implications for mother-child dyads, affected by maternal substance abuse. In N. Suchman, M. Pajulo, \& L. Mayes (Eds.), Parenting and substance abuse: Developmental approaches to intervention. New York, NY: Oxford University Press.

Lidz, T., Lidz, R., \& Rubenstein, R. (1975). An anaclitic syndrome in adolescent amphetamine addicts. Psychoanalytic Study of the Child, 31(3), 17-348. DOI:

$10.1080 / 00797308.1976 .11822320$

Luyten, P. (2017). Personality, Psychopathology, and Health Through the Lens of Interpersonal Relatedness and Self-Definition. Journal of the American Psychoanalytic Association, 65(3), 473-489. DOI: 10.1177/0003065117712518

Luyten, P., Blatt, S., \& Fonagy, P. (2013). Impairments in self structures in depression and suicide in psychodynamic and cognitive behavioral approaches: implications for clinical practice and research. International Journal of Cognitive Therapy, 6(3), 265-279. DOI: 10.1521/ijct.2013.6.3.265 
Morgenstern, J., \& Leeds, J. (1993). Contemporary psychoanalytic theories of substance abuse: A disorder in search of a paradigm. Psychotherapy, 30(2), 194-206. DOI: 10.1037/00333204.30.2.194

Pines, D. (1972). Pregnancy and motherhood: Interaction between fantasy and reality. British Journal of Medical Psychology, 45, 333-343. DOI: 10.1111/j.2044-8341.1972.tb02216.x

Priel, B., \& Besser, A. (2001). Bridging the gap between attachment and object relations theories: A study of the transition to motherhood. British Journal of Medical Psychology, 74, 85-100. DOI: $10.1348 / 000711201160821$

Raphael-Leff, J. (1996). Pregnancy_Procreative Process, The "Placental Paradigm,” and perinatal therapy. Journal of the American Psychoanalytic Association, 44S, 373-399.

Rodning, C., Beckwith, L., \& Howard, J. (1992). Quality of attachment and home environments in children prenatally exposed to PCP and cocaine. Development \& Psychopathology, 3, 351-366. DOI: 10.1017/S0954579400007562

Rutherford, H., \& Mayes, L. (2017). Parenting and addiction: Neurobiological insights. Current Opinion in Psychology, 15, 55-60. DOI: 10.1016/j.copsyc.2017.02.014

Rutherford, H. Potenza, M., \& Mayes, L. (2013). The neurobiology of addiction and attachment. In N. Suchman, M. Pajulo, \& L. Mayes (Eds.), Parenting and substance abuse: Developmental approaches to intervention. New York, NY: Oxford University Press

Rutherford, H., Williams, S., Moy, S., Mayes, L., \& Johns, J. (2011). Disruption of maternal parenting circuitry by addictive process: rewiring of reward and stress systems. Frontiers in Psychiatry, 2, 37. DOI: 10.3389/fpsyt.2011.00037 
Salo, S., \& Flykt, M. (2013). The impact of parental addiction on child development. In N. Suchman, M. Pajulo, \& L. Mayes (Eds.), Parenting and substance abuse: Developmental approaches to intervention. New York, NY: Oxford University Press.

Sayre, J., Pianta, R., Marvin, R., \& Saft, E. (2001). Mothers' representations of relationships with their children: Relations with mother characteristics and feeding sensitivity. Journal of Pediatric Psychology, 26(6), 375-384. DOI: 10.1093/jpepsy/26.6.375

Shahar, G., \& Mayes, L. (2017). Cognitive-Humanistic Psychodynamics: Sidney Blatt's Theoretical-Philosophical Legacy. Journal of the American Psychoanalytic Association, 65(3), 457-472. DOI: 10.1177/0003065117709013

Sinha, R. (2001). How does stress increase the risk of drug abuse and relapse? Psychopharmacology, 158, 343-359. DOI: 10.1007/s002130100917

Siqveland, T., Haabrekke, K., Wentzel-Larsen, T., \& Moe, V. (2014). Patterns of mother-infant interaction from 3 to 12 months among dyads with substance abuse and psychiatric problems. Infant Behavior and Development, 37, 772-786. DOI:

10.1016/j.infbeh.2014.09.003

Slade, A., Belsky, J., Aber, L., \& Phelps, J. (1999). Mothers' representations of their relationships with their toddlers: Links to adult attachment and observed mothering. Developmental Psychology, 35(3), 611-619.

Soenens, B., Vansteenkiste, M., \& Luyten, P. (2010). Toward a domain-specific approach to the study of parental psychological control: Distinguishing between dependency-oriented and achievement-oriented psychological control. Journal of Personality, 78(1), 217-256. DOI: 10.1111/j.1467-6494.2009.00614.x 
Sokolowsky, M., Hans, S., Bernstein, V., \& Cox, S. (2007). Mothers' representations of their infants and parenting behavior: Associations with personal and social-contextual variables in a high-risk sample. Infant Mental Health Journal: Official Publication of The World Association for Infant Mental Health, 28(3), 344-365. DOI: 10.1002/imhj.20140

Sorenson, D., \& Schuelke, P. (1999). Fantasies of the unborn among pregnant women. $M C N$ : The American Journal of Maternal/Child Nursing, 24(2), 92-97.

Speranza, A., Nicolais, G., Vergano, C., \& Dazzi, N. (2017). Emerging criteria for the lowcoherence cannot classify category. Attachment \& Human Development, 19(6), 613-634. DOI: $10.1080 / 14616734.2017 .1355396$

Spitz, R., \& Wolf, K. (1946). Anaclitic depression: An inquiry into the genesis of psychiatric conditions in early childhood, II. The Psychoanalytic Study of the Child, 2(1), 313-342. DOI: $10.1080 / 00797308.1946 .11823551$

Suchman, N., DeCoste, C., Castiglioni, N., McMahon, T., Rounsaville, B., \& Mayes, L. (2010). The Mothers and Toddlers Program, an attachment-based parenting intervention for substance using women: Post-treatment results from a randomized clinical pilot. Attachment \& Human Development, 12(5), 483-504. DOI: 10.1080/14616734.2010.501983

Suchman, N., DeCoste, C., McMahon, T., Dalton, R., Mayes, L., \& Borelli, J. (2017). Mothering From the Inside Out: Results of a second randomized clinical trial testing a mentalizationbased intervention for mothers in addiction treatment. Development and Psychopathology, 29(2), 617-636. DOI: 10.1017/S0954579417000220

Suchman, N., McMahon, T., DeCoste, C., Castiglioni, R., \& Luthar, S. (2008). Ego development, psychopathology, and parenting problems in substance-abusing mothers. American Journal of Orthopsychiatry, 78(1), 20-28. DOI: 10.1037/0002-9432.78.1.20 
Suchman, N., DeCoste, C., Leigh, D., \& Borelli, J. (2010). Reflective functioning in mothers with drug use disorders: Implications for dyadic interactions with infants and toddlers. Attachment \& Human Development, 12(6), 567-585. DOI: 10.1080/14616734.2010.501988

Suchman, N., Decoste, C., Rosenberger, P., \& McMahon, T. (2012). Attachment-based intervention for substance-using mothers: A preliminary test of the proposed mechanisms of change. Infant Mental Health Journal, 33, 360-371. DOI: 10.1002/imhj.21311

Suchman, N., \& Luthar, S. (2000). Maternal addiction, child maladjustment, and sociodemographic risks: Implications for parenting behaviors. Addiction, 95(9), 1417-1428. DOI: $10.1046 / \mathrm{j} .1360-0443.2000 .959141711 . x$

Suchman, N., \& Luthar, S. (2001). The mediating role of parenting stress in the methadone maintained mothers' parenting. Parenting: Science and Practice, 1(4), 285-315. DOI: 10.1207/S15327922PAR0104_2

Sweet, A. (2013). Thoughts without a thinker, mimetic fusing and the anti-container considered as primitive defensive mechanisms in the addictions. Psychoanalytic Psychotherapy, 27(2), 140-153. DOI: 10.1080/02668734.2013.775181

Tops, M., Koole, S., IJzerman, H., \& Buisman-Pijlman, F. (2014). Why social attachment and oxytocin protect against addiction and stress: Insights from the dynamics between ventral and dorsal corticostriatal systems. Pharmacology, Biochemistry and Behavior, 119, 39-48. DOI: $10.1016 /$ j.pbb.2013.07.015

von Mohr, M., \& Mayes, L., \& Rutherford, H. (2017). The transition to motherhood: Psychoanalysis and neuroscience perspectives. The Psychoanalytic Study of the Child, 70:1, 154-173. DOI: 10.1080/00797308.2016.1277905 
Winnicott, D. (1960). The theory of the parent-infant relationship. International Journal of Psychoanalysis, 41, 585-595. 